\title{
EI Instituto de Estudios Peruanos: de la ambición teórica de los años sesenta al estupor fáctico ante el fujimorismo
}

\author{
Juan Martín Sánchez. \\ Escuela de Estudios Hispano-Americanos. CSIC
}

En el presente artículo se hace una revisión de la bibliografía en ciencias sociales que ha producido el Instituto de Estudios Peruanos (IEP) de Lima desde 1964 a 2000. Se mantiene una hipótesis como guía de lectura, según la cual esta producción habría evolucionado desde los diversos intentos de conseguir una interpretación integral del Perú en su historia, sociedad, economía y política (de 1964 a 1987 aproximadamente), hasta el desborde de este propósito teórico para producir múltiples estudios con diferentes perspectivas y objetos de investigación menos ambiciosos. Esta lectura se centra en las diversas colecciones bibliográficas que ha desarrollado el IEP, en las principales tesis de interpretación integral que se dieron en la bibliografía, y en las más recientes publicaciones sobre los años noventa y la falta de una imagen integral del Perú desde las ciencias sociales. En esta evolución, se detectan algunos cambios de temas y preocupaciones en la investigación, algunas continuidades en las formas de argumentar y el constante esfuerzo de los investigadores del IEP por participar, con su trabajo, en la mejora democrática del Perú.

Cualquier revisión general de la bibliografía en ciencias sociales publicada en Perú desde los años sesenta, tendrá que dedicar un capítulo especial a la producción que el Instituto de Estudios Peruanos (casi más conocido por sus siglas, IEP) ha logrado a lo largo de sus 37 años de investigación, formación y difusión.

Con este texto pretendo hacer un esbozo de lo que podría ser ese capítulo importante en un estudio más general. Pero sobre todo quiero indagar sobre las líneas básicas de la evolución de las publicaciones del IEP y cómo ofrecieron algunas de las principales interpretaciones sobre el Perú contemporáneo (también algunas de las más destacadas lecturas del Perú colonial y prehispánico, pero éstas no serán tenidas en cuenta en mi reseña por escapar a mi competencia). Finalmente, y ésta es la parte más importante, dedicaré un mayor espacio al comentario crítico de las ultimas publicaciones que ha producido el Instituto en el cierre de una década de oprobio fujimorista.

\section{Breve presentación de la labor del IEP}

El Instituto de Estudios Peruanos dispone de una buena página web en Internet (http://iep.perucultural.org.pe/) que presenta con claridad y conci- 
sión la mayor parte de sus objetivos, historia, actividades, organización, personal, proyectos de investigación y publicaciones. Pero ya se va haciendo necesario un trabajo monográfico sobre el IEP que abarque todos esos temas en mayor profundidad. Éste es un tipo de estudio que apenas se ha desarrollado en Perú, y que por el peso que el IEP u otros centros de investigación y formación similares han tenido en la conformación de una imagen más o menos dominante dentro y fuera del Perú, con significativas repercusiones políticas, sería de gran interés intelectual y sociopolítico. Por ello, y sin suplir ese vacío, tomaré nota de tres aspectos centrales e imbricados en la vida del Instituto: investigaciones, formación y publicaciones.

En el primer rubro habría que destacar el siempre difícil esfuerzo de compaginar las interpretaciones globales sobre el Perú — por ejemplo, el debate sobre el predominio oligárquico o extranjero en la historia del Perú que tuvo lugar entre los años sesenta y setenta - con la investigación empírica y el trabajo de campo - estudios de comunidades indígenas o el detalle de las reformas industriales del gobierno militar-. Buena parte de este esfuerzo iba unido al programa de trabajo de alguno de los investigadores principales del Instituto, como Jorge Bravo Bresani, Alberto Escobar, José Matos Mar o Julio Cotler. Y el objetivo central que aglutinaba a buena parte de las investigaciones, al menos hasta mediados de los años ochenta, era explicar la tortuosa relación entre la sociedad nacional desestructurada, diversa y con graves problemas de comunicación, tanto culturales como geográficas, y un Estado que no terminaba de ser oligárquico y dependiente sin lograr la democratización de sus instituciones. Predominó el estudio de la primera parte de la ecuación — esa sociedad coloidal, fracturada por la oligarquía y la dependencia - en trabajos sobre la sociedad rural, las reformas agraria e industrial, las migraciones interregionales o la urbanización; mientras, se descuidó el estudio de los requerimientos institucionales del Estado, con sus problemas administrativos, jurídicos, fiscales, etc. - no hay trabajos sobre el proceso constituyente de 1978-1979, sobre el entramado constitucional y práctico que consolidan el presidencialismo o sobre el Poder judicial, incluso pocos sobre los militares-.

Hasta cierto punto, la evolución anterior cambió hacia la segunda mitad de los años ochenta en que comenzó una mayor diversificación de los temas y áreas tratados, aunque perdiendo en sujeción teórica. Con la crisis económica que no toca fondo y el impreciso desarrollo democrático, se amplían los estudios económicos y se da mayor importancia a las vías institucionales de participación política. Por supuesto que en este giro tuvo su 
influencia el mayor margen de maniobra que había ganado la izquierda partidaria en el régimen político peruano, con una fuerza electoral ascendente y previsibles opciones de gobierno. Esto es más claro si se tiene en cuenta que el IEP había sido fundado por investigadores de clara filiación progresista de izquierdas y que ha tratado de mantener esa orientación aunque hayan cambiado los discursos. ${ }^{1}$ Con estos cambios surgieron temas de atención creciente, como la relación de los jóvenes con la política, los estudios de género, el desarrollo de Sendero Luminoso y las violencias anexas, los problemas de descentralización del Estado y la economía, el mercado informal, el empleo, los derechos ciudadanos, etc. Y aunque la parte social de la ecuación antes señalada sigue atrayendo mayor dedicación, los problemas de consolidación democrática o su cuestionamiento durante los años noventa han ganado terreno y — que tal vez sea lo más importanteautonomía.

Por otra parte, la labor investigadora del IEP, por más que se ha asentado en el trabajo de los investigadores peruanos, no se entendería bien sin tener en cuenta los muchos investigadores extranjeros que han pasado por sus salones, como el cofundador John Murra o Giorgio Alberti, Norbert Lechner, Cynthia McClintock, Abraham Lowenthal, Philip Mauceri, Catherine Conaghan, Steve Stein, etc. Al mismo tiempo, la vinculación de los propios miembros del IEP con centros de investigación extranjeros ha sido constante y fructífera. De esta doble comunicación hacia dentro y hacia fuera se ha nutrido la producción propia del IEP y es un factor a tener en cuenta para cualquier estudio de la misma.

En la actualidad, parece consolidada esta mayor diversidad de temas y perspectivas de investigación, desde los diversos proyectos que acoge el programa institucional sobre "Descentralización, desarrollo y democracia en el Perú" (descentralización fiscal, encuestas, reformas del Estado, etc.) hasta proyectos particulares sobre cambios en los poderes locales tras la guerra con Sendero Luminoso, estudios de pobreza y migración, cambios curriculares en la enseñanza, etc. Todos estos proyectos tienen repercusión

1 Tal vez ha aumentado la imprecisión que hace que algunas declaraciones puedan resultar extrañas, como la presentación del IEP en su página web (http://iep.perucultural.org.pe/), en que se dice: "Ajenos a toda afiliación partidaria o religiosa, los miembros del IEP desarrollan proyectos de investigación en antropología, economía, historia, sociología y política." (Subrayado mío). Es evidente que ese ajenos no es del todo real ni pretendido, otra cosa es que se trabaje con honestidad y sin dependencias partidarias, religiosas, financieras, etc., algo siempre difícil de conseguir. Sin duda que con una reivindicación progresista y democrática de la investigación objetiva, más acorde con la fundación del Instituto, la imagen corporativa de éste ganaría en claridad. 
más o menos directa en las publicaciones del IEP o en las que sus investigadores puedan colaborar con otras editoriales.

Ahora bien, en esa mayor diversidad parece que se ha perdido la ambición fundadora del trabajo multidisciplinar a favor de interpretaciones globales sobre el Perú. En los noventa, los trabajos de investigación han sido más inconexos y menos en función de alguna tesis hegemónica en la explicación. Se trabaja más desde las áreas particulares e, incluso, desde la perspectiva personal, aunque no falte la comunicación entre los investigadores. Se nota aquí también la perdida de "los grandes relatos" o teorías generales en ciencias sociales.

Una segunda dimensión fundamental en la trayectoria del IEP ha sido la formación de investigadores en ciencias sociales, apoyando a las universidades (incluso supliéndolas) y creando un espacio más intelectual que mercantil para este trabajo (aunque muchos investigadores del Instituto hacen consultorías profesionales para el mercado empresarial o institucional, éstas suelen tener un carácter paralelo al trabajo en el Instituto). En cualquier caso, casi la totalidad de los investigadores del Instituto han sido y siguen siendo (aunque con periodos de distanciamiento) profesores en alguna de las universidades de Lima, especialmente en la Universidad Mayor de San Marcos y en la Pontificia Universidad Católica del Perú (centros de donde proceden la mayoría de los asistentes y jóvenes investigadores que se incorporan al IEP).

En esta labor de formación y discusión siempre han estado muy presente las conferencias y las mesas redondas (adjetivadas como verdes por el color del tapete de las mesas). Algunas de esas sesiones han llegado a tener carácter casi de leyenda, como la que tuvo lugar el 23 de junio de 1965 sobre el libro de José María Arguedas Todas las sangres, editada en 1985 por Alberto Escobar (cofundador del Instituto y participante en aquella mesa) en el IEP y reeditada bajo el cuidado de Guillermo Rochabrún en el 2000. ${ }^{2}$ Incluso son muchas las ocasiones en que el Instituto convoca a una reunión de debate a propósito de alguna coyuntura especialmente difícil de la vida peruana. En esas reuniones se juntan investigadores, políticos y personalidades en general en un formato de conversación más o menos abierto y siempre productivo.

2 Escobar, Alberto (editor): He vivido en vano, Lima, 1985. Rochabrún, Guillermo (editor): La mesa redonda sobre "Todas las sangres", Lima, 2000. Este libro fue el más importante esfuerzo de Arguedas por dar una lectura integral del Perú que él había vivido. Su siguiente proyecto, de equivalente ambición, El zorro de arriba y el zorro de abajo, quedó inconcluso con la muerte de su autor que no alcanzó a vivir lo suficiente para compartir nuevas lecturas menos "militantes" de su obra literaria. 
Pero el camino más fecundo en cuanto a formación se refiere es el que emprendió el IEP desde comienzo de los noventa con talleres de formación, seminarios de postgrado en ciencias sociales, promoción de becas y proyectos para jóvenes investigadores, etc. Además se participa en varias redes de desarrollo de las investigaciones sociales como son el Consorcio para la investigación económica y social, la Red para el desarrollo de las ciencias sociales en el Perú o el Consorcio para el desarrollo de la ecoregión andina.

Finalmente, respecto del trabajo editorial del IEP es importante hacer algunos comentarios sobre sus diversas colecciones y las propuestas que subyacen a éstas. En total son ya unos 350 títulos en el momento de escribir este artículo (es difícil acertar con la cifra exacta, pues hay varios trabajos en prensa que ya podrían estar en la calle). Más otros 110 documentos de trabajo y la publicación mensual de la revista Argumentos. Boletín de coyuntura política y económica, desde enero de 1993 hasta mediados de 1996.

La distribución de estos títulos a lo largo de las diversas colecciones es como se presenta en el siguiente cuadro. He tratado de identificar los años de mayor número de obras publicadas en cada colección, con el propósito de dar una imagen, aunque sea somera - pues no entro a indagar sobre las causas de esta distribución estadística一, de la evolución editorial del IEP.

PUBLICACIONES DEL IEP POR COLECCIÓN, ENTRE 1964 Y 2000

\begin{tabular}{lccc} 
Título de la Colección & Total & Año inicio & $\begin{array}{c}\text { Años de más } \\
\text { publicaciones }\end{array}$ \\
\hline $\begin{array}{l}\text { Análisis económico } \\
\text { Urbanización migraciones y cambios } \\
\quad \text { en la sociedad peruana }\end{array}$ & 20 & 1964 & $81-94: 13$ \\
$\quad \begin{array}{l}\text { Fuentes de investigación para } \\
\quad \text { la historia del Perú }\end{array}$ & 15 & 1966 & $84-87: 5 / 91: 3$ \\
$\quad$ Estudios de la sociedad rural & 13 & 1966 & $66-70: 3 / 78-83: 4$ \\
$\quad \begin{array}{l}\text { América Problema } \\
\text { Perú Problema }\end{array}$ & 18 & 1967 & $67-83: 10 / 94-99: 7$ \\
$\quad$ Estudios etnológicos del valle & 16 & 1967 & $68-80: 11 / 89-93: 5$ \\
$\quad$ de Chancay & 27 & 1968 & $68-84: 21$ \\
$\quad \begin{array}{l}\text { Guías bibliográficas } \\
\text { Actualidad }\end{array}$ & 7 & 1968 & $68-75: 6$ \\
$\quad \begin{array}{l}\text { Estudios Históricos } \\
\text { Actas del XXXIX Congreso }\end{array} \quad 3$ & 1971 & $71: 2$ \\
$\quad$ Internacional de Americanistas & 6 & 1971 & $75-82: 9 / 92-99: 15$ \\
& 27 & 1972 & $72-75: 6$
\end{tabular}


PUBLICACIONES DEL IEP POR COLECCIÓN, ENTRE 1964 Y 2000 (continuación)

\begin{tabular}{lccc} 
Título de la Colección & Total & Año inicio & $\begin{array}{c}\text { Años de más } \\
\text { publicaciones }\end{array}$ \\
\hline Colección mínima & 39 & 1973 & $80: 7 / 89: 4 / 91: 6$ \\
Historia andina & 22 & 1973 & $73-83: 10$ / 86-93:10 \\
Lengua y sociedad & 16 & 1974 & $76 * / 84-90: 6$ \\
Ideología y política & 12 & 1974 & $87-90: 5 / 97-99: 5$ \\
Historia social y económica & & & \\
$\quad$ del Cusco & 2 & 1979 & $79: 2$ \\
Miscelánea & 8 & 1981 & $92-95: 5$ \\
Documentos de trabajo & 110 & 1987 & $94-95: 5$ \\
Infancia y Sociedad & 5 & 1994 & \\
Lecturas contemporáneas & 1 & 1995 & \\
JCAS Occasional Paper & 3 & 1999 & \\
Turismo & 1 & 1999 & \\
\hline
\end{tabular}

* En 1976 se publicaron los 12 volúmenes de la gramática y los diccionarios quechuas.

Fuente: Catálogo de publicaciones del Instituto de Estudios Peruanos que aparece en su página web (http://iep.perucultural.org.pe/) en marzo de 2001. Elaboración propia.

Lo primero que destaca del cuadro de publicaciones es que para 1974 ya estaban en marcha todas las series importantes del IEP, aunque el segundo aspecto a señalar es la irregularidad en la producción dentro de cada serie. Colecciones tan emblemáticas del Instituto como han sido Perú Problema y América Problema ${ }^{3}$ prácticamente se cierran a comienzo de los años ochenta, para reaparecer en la coyuntura de la crisis de los años noventa en un espíritu de compilación de asideros para una democracia que se desvanece entre la guerra, la inflación y la corrupción institucional. Inversa trayectoria ha seguido la serie Ideología y Política, que para 1987 sólo tenía dos volúmenes en la calle, siendo relanzada desde esta fecha con numerosas aportaciones de investigadores externos al Instituto y con una clara preocupación por los factores de crisis del régimen democrático des-

3 Ambas toman su nombre del libro señero de Basadre, Jorge: Perú: problema y posibilidad. Ensayo de una síntesis de la evolución histórica del Perú, Lima, 1931. Éste es un libro en que Basadre se muestra especialmente optimista con la promesa de una "vida peruana", pese a los múltiples fracasos en su realización. Recogiendo este optimismo, los fundadores del IEP podrían haber titulado sus colecciones como Perú posibilidad y América posibilidad, pero parece que predominó el aspecto analítico sobre el propositivo. 
de los partidos políticos hasta las fuerzas armadas o la violencia senderista. La serie Análisis Económico distribuye sus publicaciones de forma menos concentrada, aunque se nota la influencia de los problemas económicos de la década de los ochenta. Algo interesante en esta colección es que a partir de 1987 todos los títulos están firmado por Efraín Gonzales de Olarte. Cierto que otros investigadores del área de economía han publicado sus trabajos en otras series por el tipo de investigación menos global que han realizado. ${ }^{4}$ La distribución de los trabajos de historia (Estudios de Historia, Historia Andina y Fuentes de investigación para la historia del Perú) tiene dos periodos de gran producción relativamente separados entre sí, algo que también ocurre claramente con los 18 libros de los Estudios de la sociedad rural. La serie Lengua y Sociedad, siempre alentada por el doctor Alberto Escobar, tuvo una destacada participación con los 12 volúmenes de gramáticas y diccionarios quechuas que publicó en 1976. Y la colección Urbanización, migraciones y cambios en la sociedad peruana, parece tener un comportamiento más espasmódico, aunque conexos a momentos del llamado "desborde popular", especialmente en Lima. Las demás series han tenido una temporalidad más corta y producciones más limitadas.

Por su parte, la Colección mínima con 39 textos desde 1973 y la de Documentos de trabajo con 110 desde 1987 constituyen dos series de características especiales. En el primer caso, se trata de textos en torno a las cien páginas en un formato pequeño. Estos trabajo se desprenden de investigaciones más amplias en las que participan varios investigadores, como son los libros dedicados a la reforma agraria, o responden a intentos de aclarar alguna coyuntura significativa o problema específico del país, como los producidos en torno al advenimiento de la democracia en 1980 o las elecciones de 1990. Por sus características, la Colección mínima juega muy bien el papel de avances de investigación y apertura de nuevas áreas. Es una serie donde no domina una perspectiva particular, como en Perú problema o Estudios de la sociedad rural, dejando un espacio abierto a la innovación pero sin la sensación de propuesta provisional que tienen los Documentos de trabajo.

Este último conjunto de texto es el más variado e innovador, con una producción ascendente desde que en 1987 apareciera el primer texto. El

4 En el caso del economista Francisco Verdera, ya se echa en falta una amplia monografía sobre el empleo y las relaciones laborales en el Perú que reúna dos décadas de investigación fructífera en datos, metodología y perspectiva. Sus textos están dispersos en libros colectivos y documentos de trabajo. 
mismo IEP clasifica los documentos según el área de investigación, logrando el siguiente reparto: Economía 35, Sociología y política 26, Historia 17, Antropología 12, Talleres (seminarios de formación) 6, Política 6, Etnohistoria 2, Historia del arte 2, Lingüística 2, Estudios de género 1. Muchos de estos trabajos terminan formando parte de alguno de los libros de las principales colecciones del Instituto, habiendo servido como borrador de discusión de los trabajos de investigadores noveles, como Carlos Vargas y Patricia Ames, de investigadores ya veteranos, como Carlos Contreras, Alberto Escobar, Francisco Verdera, o para difundir alguna propuesta de algún investigador visitante, como Abraham Lowenthal y Fernando Henrique Cardoso. Las características de la serie, más cuaderno que libro, ayudan a su carácter de indagación y debate, sin por ello perder profundidad. Sin duda ésta es una muy buena estrategia para la consecución de los objetivos que persigue el IEP, mucho más flexible que la publicación de una revista y que, con las nuevas tecnologías de la comunicación, ganará mayor dinamismo (ya se pueden consultar algunos de estos documentos de trabajo directamente en la página web del IEP, aunque aún son pocos).

\section{Principales tesis y debates en las publicaciones del IEP hasta 1992}

En este apartado quiero plantear los rasgos básicos de cuatro momentos especialmente ricos en la discusión de ciencias sociales en el Perú. Lo que me interesa es crear el tapiz de fondo para la discusión de la bibliografía reciente sobre la década de Fujimori. Estos cuatro momentos tuvieron varias publicaciones emblemáticas y sobre ellas basaré mi esbozo.

El primer momento tiene mucho que ver con la década en que se funda el Instituto de Estudios Peruanos, mediados de los años sesenta. El objetivo era conseguir una imagen interdisciplinal del Perú de esos años de rápida modernización económica y urbana pero con enormes límites a la aplicación de políticas reformistas que afectaran al grueso de la población. Hacia esos límites se dirigiría la mayoría de las investigaciones tratando de encajar las características principales del Perú en algún modelo teórico identificable. Y tres fueron las figuras más solicitadas: la oligarquía, la dependencia y la sociedad rural. Con las dos primeras, los autores trataban de subrayar el factor clave para entender la situación histórica del Perú que, en parte, se plantearon con rasgos opuestos. De este debate dan buena cuenta varios títulos fundamentales de las colecciones Perú Problema y 
América Problema. ${ }^{5}$ Grosso modo, los extremos de la discusión fueron establecidos por el sociólogo francés François Bourricaud y por el economista peruano Jorge Bravo Bresani. Para el primero, la oligarquía seguía existiendo en el Perú como un grupo predominantemente nacional y con gran capacidad de adaptación a las nuevas circunstancias del país, hasta el punto de no mostrarse como grupo dirigente al frente del Estado, pero sí desplegar un discurso fuerte de legitimación del orden reinante. Para ello, usarían la intermediación de diversas instancias de la administración estatal y de los grupos de clase media que las ostentaban, mientras la oligarquía se guardaba la última palabra de su poder económico y de su relación con la economía internacional. Mientras, la creciente movilización social y las migraciones a las ciudades iban erosionando las bases de poder de esa oligarquía que necesitaba transitar hacia otras actividades. Pero el dominio oligárquico no sólo era económico sino que también ordenaba la sociedad con una cultura de formas de hacer y de miedos políticos que aprisionaban la acción de gobierno (presupuestos equilibrados, racismo paternalista, desconfianza de la educación). El problema fundamental sería, entonces, la democratización de la sociedad peruana y la autonomización del Estado respecto del tradicional manejo oligárquico.

Por su parte, Jorge Bravo Bresani calificaba de mito el asunto de la oligarquía y presentaba a la inserción periférica y dependiente del Perú al incipiente capitalismo internacional, durante la época de la colonia española, primero, y luego a la economía industrial del Gran Bretaña y Estados Unidos, como la variable fundamental para entender la historia del Perú, su estructura social en los años sesenta y la vías reformistas (modernizadoras) que por esos años están intentando los grupos dirigentes más relacionados con el capital extranjero. La oligarquía no pasaría de ser la capa alta de una exigua clase media nacional que gestionaba en el Perú los intereses del capital internacional. En Bresani, la lectura histórica de largo recorrido era casi tan importante como el análisis de la estructura social. Los principales problemas desde esta perspectiva eran el atraso del país respecto al exterior, el carácter subsidiario de una economía abocada a la exportación de mate-

5 La colección América Problema fue una importante puerta de entrada para los textos de importantes autores de la teoría de la dependencia, como Celso Furtado, Aníbal Pinto, Marcos Kaplan o Teothonio Dos Santos. Uno de los investigadores más destacados del IEP en sus primeros años, Aníbal Quijano, se convertiría, por méritos propios, en un destacado autor de la teoría de la dependencia. La recuperación a fines de los años ochenta de esta colección, estaría más cercana a problemas de movilización social, desarrollo y consolidación de la democracia en América latina, con mayor peso de autores como Alain Touraine, Norbert Lechner o Fernando Calderón. 
rias primas, la desconexión de gran parte del país del circuito económico dominante y la falta de relación entre una nación fragmentada (coloidal que alguna vez dijera) y un Estado más orientado a las demandas del capital externo que a la integración de la sociedad peruana. ${ }^{6}$

El acento en una lógica de la dominación más nacional o más dependentista diferenciaba a diversas posturas intermedias. En general, las investigaciones del IEP estuvieron más cerca de una lectura dependentista, pero el desarrollo de los estudios sobre la sociedad rural —en muchos casos, trabajos monográficos de regiones concretas del país- ampliaron la visión a contradicciones y factores escurridizos para el tamiz oligárquico o externo. Se trataba de la importancia de culturas y formas de producción regionales fuertemente asentadas y que reenviaban muchas interpretaciones a los estudios locales. Fernando Fuenzalida y José Matos Mar destacarían en estas indagaciones desde la antropología y la sociología. Pero también lo haría Alberto Escobar (junto a otros filólogos) con el estudio regionalizado del quechua -idioma que con el gobierno militar sería oficializado como lengua del Perú junto al castellano- o los trabajo de etnohistoria de María Rostworowski o John Murra que le daría otro calado histórico a la diversidad social del Perú. Tal vez, en estos estudios de la sociedad rural — concepto mucho más amplio que el de sociedad agrícola- y del mundo andino no había una tesis teórica dominante, pero sí cartografiaron un extensísimo espacio histórico-social del que se había escrito poco. Esa cartografía tendría una gran importancia en los estudios siguientes y en la interpretación de las reformas militares.

En efecto, el segundo momento importante en la trayectoria del IEP estaría marcado por la necesidad de explicar el ímpetu reformista de unos militares, presididos por el general Juan Velasco Alvarado, que durante el siglo XX habían sido el dique seguro contra las movilizaciones sociales y desde 1969 parecían el ariete histórico contra la oligarquía. La nacionalización de la estadounidense International Petroleum Company, las reformas agraria, industrial, educativa o la intervención de la prensa, tan fuertemente asociada al poder oligárquico, crearían un terreno muy movedizo para el

6 El libro que mejor recoge el debate y en el que participaron otros dos autores con propuestas, en cierto modo, intermedias a las anteriormente expuestas, es: Bourricaud, François; Bravo Bresani, Jorge; Favre, Henri, y Piel, Jean: La oligarquía en el Perú, 3 ensayos y una polémica, Lima, 1969. De estos cuatro autores se pueden encontrar otras obras en los catálogos del IEP, pero habría que subrayar un trabajo especialmente importante por su calidad de interpretación global de la sociedad peruana previa al gobierno militar y que el IEP reedito en 1989 con una interesantísima presentación del autor; me refiero a Bourricaud, François: Poder y sociedad en el Perú, Lima, 1989. 
posicionamiento intelectual: desde la colaboración de Augusto Salazar Bondy o la simpatía de Jorge Bravo Bresani, hasta la crítica de Julio Cotler o la confrontación abierta de Aníbal Quijano.7 Sin duda fueron años difíciles para el Instituto que se abocó al estudio detallado de las principales reformas del gobierno y a sus efectos en la estructura social del país. La reforma agraria fue la que más dedicación ocupó, con detallados trabajos de Elena Álvarez, José María Caballero, José Manuel Mejía o José Matos Mar. Esta reforma parecía tocar los elementos fundamentales de una sociedad tradicional a la que se habían dedicados los estudios de la sociedad rural.

Pero el trabajo más importante de esta época lo realizaría Julio Cotler desde su exilio en México. El libro Clases, estado y nación en el Perú, ${ }^{8}$ de 1978, sería la primera interpretación integral del desarrollo socio-histórico del país que lograba el IEP. El libro había sido pensado para explicar el reformismo militar del gobierno de Juan Velasco Alvarado, pero pronto abarcó un proyecto que juntaba los principales debates intelectuales habidos en el Perú durante los años sesenta y parte de los setenta. Cotler establece una continuidad histórica básica entre el siglo XVI de la conquista y la reorganización del poder tras la independencia en el XIX para explicar tanto la consuetudinaria dependencia externa del Perú respecto del desarrollo capitalista de los países del norte, como el carácter colonial que tenía la dominación oligárquica interna en el país. Ambos factores dibujaban un mapa poderoso para la navegación intelectual y política: un archipiélago con oligarquías insulares y compañías extranjeras que explotaban productos de exportación sin crear mayores encadenamientos socioeconómicos horizontales; una sociedad coloidal que requería de la permanente intervención de un modelador providencial que le diera forma al Estado-nación, un papel que asumirían los militares del 68 ante la incapacidad de las clases civiles dominantes.

El libro del Cotler tuvo una gran acogida y difusión por lo sugerente del modelo interpretativo, esa pirámide sin base que permitía conectar las investigaciones locales con propuestas más globales de la sociedad peruana y, desde aquí, volver a bajar hacia la fragmentada estructura social con políticas de reforma más concretas. Ante esta fuerza del modelo, las críti-

7 Estos dos últimos dirigían una revista de análisis de coyuntura, Sociedad y política, que molestaba mucho al gobierno militar hasta requisar la revista y luego deportar a sus editores el 6 de octubre de 1973.

8 Este libro sería el número 17 de la colección Perú problema y tendría en sí algo del espíritu del libro de Basadre, Jorge: Perú: problema y posibilidad. 
cas a la propuesta serían rebotadas a la discusión sin alternativas. Fue el caso de las que hiciera Guillermo Rochabrún, un autor siempre próximo al IEP. En general, Rochabrún cuestionaba la capacidad integradora del modelo de Cotler poniendo contradicciones en los engranajes de su sistema, o como llega a decir: "El resultado que produce un concepto que no es más que una metáfora [se refiere al fracaso de una consolidada unidad nacional] es que se fija sólo en los hechos de su mismo signo, mientras que los de signo contrario - en este caso los que podrían mostrar algo de unidad - si bien pueden ser reconocidos, no cobran significación alguna y no generan problemas que merezcan ser explicados". ${ }^{9}$ Pese a lo implacable de algunas de esas críticas, el libro sigue teniendo una muy buena acogida con ediciones sucesivas, pese a que el propio autor, Julio Cotler, se ha distanciado de aquella interpretación.

El tercer momento de investigación vendría con los efectos de las transformaciones introducidas por el gobierno militar en la historia del Perú ${ }^{10}$ y con el advenimiento de una democracia incierta. El periodo en que los civiles debían recuperar la dirección del Estado, con el regreso a la presidencia de Fernando Belaúnde Terry, el Perú sufriría enormes desestabilizaciones: una breve guerra fronteriza con el Ecuador en 1981 con la que el ejército recupera prestigio y visibilidad; un fenómeno de El Niño especialmente catastrófico en 1983; una guerrilla sanguinaria e invisible en la Sierra con los consiguientes estados de emergencia e intervención militar directa desde diciembre de 1982; una crisis económica inabordable y sin fondo; y un gobierno civil que tendrá como único objetivo político desde julio de 1983 el pasar la banda presidencial a otro civil, quedando como abanderado de la democracia y, por supuesto, de la ingobernabilidad.

Con ese telón de fondo y con cierta sensación de que con el regreso del Acción Popular al gobierno el Estado no se había dado por enterado de las impresionantes transformaciones sociales del Perú en los años setenta,

9 Rochabrún, Guillermo: "La visión del Perú de Julio Cotler. Un balance crítico", Análisis: cuadernos de investigación, núm. 4, enero-abril, Lima, 1978, pág. 73. Además de estas cuestiones de metodología, una de las principales críticas tocaba de lleno a la tesis principal de la continuidad sin rupturas de la herencia colonial hasta el Perú actual. Máxime si el capítulo dedicado a la época colonial era el más débil de todo el libro y su interpretación totalmente sometida a demostrar el vacío de poder en el que se produce la independencia y posterior reorganización del país.

10 El más importante balance que se ofrece desde el IEP del gobierno militar es el libro colectivo: McClintock, Cynthia (comp.); Lowenthal, Abraham F. (comp.); Cotler, Julio; Thorp, Rosemary; FitzGerald, E. V. K.; Schydlowsky, Daniel/Wicht, Juan; Stallings, Barbara; Guasti, Laura; Cleaves, Peter S./Pease, Henry; North, Liisa; Pásara, Luis; Eckstein, Susan, y Sheahan, John: El gobierno militar. Una experiencia peruana 1968-1980, Lima, 1985, 466 págs. 
el IEP publica una importante cantidad de trabajos que tratan de "descubrir" la realidad de esos cambios. Son los años en que más textos aparecen en la colección Urbanización, migraciones y cambios en la sociedad peruana, especialmente dedicados al crecimiento de Lima y sus infinitos "pueblos jóvenes". Pero también aumenta el número de publicaciones en la serie Análisis económico con cierta dedicación a las economías regionales $\mathrm{y}$ al estudio del empleo.

En ese ambiente sociopolítico e intelectual, José Matos Mar publicaría en el primer trimestre de 1984 un ensayo catalizador: Desborde popular y crisis del Estado. El nuevo rostro del Perú en la década de 1980. Si la de Cotler había sido una obra extensa, con amplia bibliografía, en un estilo casi de tesis doctoral, una historia sociopolítica del Perú a la búsqueda del presente, el ensayo de Matos es su reverso, un texto pequeño, sin bibliografía, fuentes o citas, muy afirmativo y con pretensiones apodícticas, seductor y claro, sumamente apologético, un diagnóstico coyuntural en busca de causas históricas y de futuros normativos. Sin duda, el trabajo de Matos Mar, al que contribuyeron los esfuerzos de muchos investigadores del IEP, es brillante y tuvo una enorme eficacia. ¿Cuál era su tesis principal? En su propias palabras:

En estas condiciones [las que más arriba he enumerado], la crisis actual no es coyuntural sino estructural. Estamos frente a un insólito y espontáneo proceso de transformación. Un cambio producido por combinación entre el intenso crecimiento demográfico, la explosión de las expectativas, el mayor acceso de las masas a la información, la urbanización sin industrialización y una crisis económica sin precedentes. Un estado en crisis, sin capacidad para responder a la presión de necesidades de las masas, casi sin interlocutor, con un serio vacío de poder y débil legitimidad; que enfrenta a un pueblo que cuestiona y desarrolla creativamente múltiples estrategias de supervivencia y acomodo, contestando y rebasando el orden establecido, la norma, lo legal, lo oficial, lo formal. ${ }^{11}$

Las causas remotas de tal diagnóstico estarían en el carácter "inconcluso" de la nación peruana, desde la subordinación cultural, militar y económica que trajo consigo la conquista española, hasta el colonialismo interior de la oligarquías republicanas. El momento de quiebra y emergencia de la estructura social del nuevo Perú sería la década de los 50 con la industrialización incipiente, las movilizaciones campesinas, las migraciones a la ciudad, la preeminencia popular del cholo, las nuevas ofertas par-

11 Matos Mar, José: Desborde popular y crisis del Estado. El nuevo rostro del Perú en la déca-

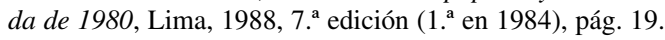


tidarias reformistas con anuencia en sectores de clase media alta. Le seguirían la intervención nacionalista reformista de los militares entre 1968 y 1975 y la posterior retirada a los cuarteles en medio de la crisis económica, la incapacidad burguesa para concreta un proyecto nacional eficiente y la mayor movilización popular del Perú contemporáneo.

De nuevo, la metáfora, la imagen sugestiva, parece ganar el lugar de la argumentación. Matos Mar ofrecía la retransmisión en directo de un "alumbramiento" 12 social: señala la violenta fecundación de la conquista, la larga gestación colonial con sus posteriores riesgos sietemesinos de la débil república, las contracciones del encaje (o mejor desencaje, por lo contradictorio del proceso) en los años 50 a 70 , y el rompimiento de la matriz estatal a mediados de los 80 .

En el nuevo Perú, la distancia entre el Estado burgués, con su democracia convencional, y la sociedad emergente se convierte en ruptura y colisión. Aquí, la falta de un "proyecto nacional" desde las clases dominantes legitima una irrupción social sin necesidad de más alternativa que su presencia, que vislumbra, que evidencia, un futuro socialista. Hoy, tras la década del oprobio fujimorista, podríamos decir, siguiendo con la metáfora del alumbramiento, que el parto no se produjo en las mejores condiciones higiénicas y que bastante de las enfermedades estatales fueron transmitidas al vástago social, que la madre estatal hubiera necesitado mayores atenciones sanitarias, algún plan de descanso por maternidad, mejores alimentos fiscales, certificación profesional de la atención al parto, de los ministerios, de los presupuestos, del Poder judicial, de las investigaciones sociales. Para finales de los ochenta, del Estado peruano parece que sólo quedaban los leucocitos militares y su cóctel de medidas terapéutica del "Plan verde". ${ }^{13}$

El cuarto y último momento que presento en este artículo está marcado por la creciente preocupación por las necesidades institucionales de la democracia, obviamente inspirado por lo que a todas luces parecía, desde

12 Esta figura del "alumbramiento" sería explícitamente defendida por otro investigador social peruano, Carlos Franco, en su ensayo Imágenes de la sociedad peruana: la «otra» modernidad, Lima, 1991. Este investigador pertenece al Centro de Estudios para el Desarrollo y la Participación, otro de los institutos importantes en los estudios sociales del Perú, formado por un significativo grupo de colaboradores civiles del gobierno de Juan Velasco Alvarado. Desde fines de los setenta, publican la revista Socialismo y participación.

13 Fernando Rospigliosi hace un análisis del Plan verde de las fuerzas armadas peruanas, diseñado como programa para un eventual golpe de estado, en su documento de trabajo del IEP, Las fuerzas armadas y el 5 de abril. La percepción de la amenaza subversiva como motivación golpista, Lima, 1996. 
1987, una crisis irreversible del régimen político. El gobierno de Alan García trastabillaba a cada paso. La incontrolable inflación y la guerra con Sendero Luminoso estaban dejando al Estado y la sociedad exhaustas, por lo que el peligro de un golpe de estado se sentía inminente. En todos estos frentes trató de estar el IEP buscando, casi desesperadamente, como "salvar la democracia". En 1987, Julio Cotler compila una serie de artículos bajo el significativo título Para afirmar la democracia. Poco después, desde 1989, se inicia en la colección América Problema, una serie de libros compilatorios con el denominador común de la democracia (y socialismo, y economía, y violencia, y autoritarismo). ${ }^{14}$ Una serie de gran calidad que traía al IEP y al Perú un conjunto de debates de toda América latina que se podrían englobar en el esfuerzo que Norbert Lechner llamaría "De la revolución a la democracia". ${ }^{15}$ En el centro de estos debates estaba el intento de establecer una lógica política autónoma de la democracia y no sometida a las necesidades sociales, históricas o culturales, lo que suponía — para las tradiciones intelectuales progresistas marcadas por el marxismo-, renunciar a la explicación socioeconómica en "última instancia" (y ya puestos, romper con el pensamiento teleológico de un futuro como "promesa" de una vida buena).

En esta etapa de la producción del IEP — que tal vez aún sigue abierta - no se ha alcanzado ninguna interpretación global del Perú como las que jalonaban la colección Perú Problema. De hecho, esta serie estuvo detenida desde la publicación de Desborde popular, en 1984, hasta 1993, que se publicara el sintomático libro de Max Hernández Memoria del bien perdido. Conflicto, identidad y nostalgia en el Inca Garcilaso de la Vega.

14 Calderón, Fernando (comp.); Aricó, José; Calderón, Fernando; Dos Santos, Mario R.; Furet, François; Gianotti, José Arthur; Guerra, François-Xavier; Lechner, Norbert; Rosanvallon, Pierre, y Touraine, Alain: Socialismo, autoritarismo y democracia, Lima, 1989.

Cotler, Julio (comp.); Nun, José; Singer, Paul; Moulian, T./Letelier, L.; Rospigliosi, Fernando, y Sánchez León, Abelardo: Clases populares, crisis y democracia en América Latina, Lima, 1989.

Cotler, Julio (comp.); Borón, Atilio; Bustamante, Luis; Cardoso, Fernando H.; Franco, Carlos; Hunneus, Carlos; Karl, Terry; Mayorga, René; Sadrústegui, Miguel, y Weffort, Francisco: Estrategias para el desarrollo de la democracia en Perú y América Latina, Lima, 1990.

Gonzales de Olarte, Efraín (comp.); Alburquerque, Francisco; Berry, Albert; Figueroa, Adolfo; Iguíniz, Javier; Sunkel, Oswaldo, y Thorp, Rosemary: Nuevos rumbos para el desarrollo del Perú y América Latina, Lima, 1991.

Adrianzén, Alberto; Blanquer, Jean Michel; Calla, Ricardo; Degregori, Carlos Iván; Gilhodes, Pierre; Guerrero, Andrés; Husson, Patrick; Lavaud, Jean Pierre; León Trujillo, Jorge; Montoya, Rodrigo; Pécaut, Daniel; Pizarro, Eduardo, y Rocha, Alberto: Democracia y etnicidad en los países andinos, Lima, 1993.

15 Lechner, Norbert: Los patios interiores de la democracia, México, 1995. 
Incluso para la celebración del treinta aniversario de la fundación del IEP en 1994, todo lo que se logró fue una ecléctica compilación de ensayos editados por Julio Cotler en 1995 bajo el genérico título Perú 1964-1994. Economía, sociedad y política. ${ }^{16}$

Tan sólo el trabajo de Efraín Gonzales de Olarte y Lilian Samamé — publicado en primera edición en 1991 con el título El péndulo peruano. Políticas económicas, gobernabilidad y subdesarrollo, 1963-1990-, estaría próximo a aquellos intentos de diagnóstico y prospectiva globales para el Perú. Sin embargo sus objetivos son mucho más limitados: explicar la ineficacia de las políticas económicas seguidas en el Perú para salir del subdesarrollo y cómo, incluso, lo han agudizado. La tesis tras la imagen del péndulo es sugerente: en tanto "las políticas económicas son endógenas a largo plazo [...] la inestabilidad política ha ejercido una fuerte influencia sobre ellas y ha alimentado la inestabilidad económica, que se sustenta en el patrón económico de dos ejes desarticulados (exportaciones e industria), patrón que es muy fluctuante". ${ }^{17}$

En su análisis de la evolución de las políticas económicas, Gonzales y Samamé no sólo tienen en cuenta las variables económicas nacionales e internacionales (producción por sectores, empleo, inflación, exportaciones e importaciones, precio del dinero, deuda, etc.), sino que asumen la agenda política como variable relativamente independiente en el análisis económico, pese a las constricciones que ésta pueda tener. De esta manera encuentran que las políticas económicas han oscilado entre programas intervencionistas por parte del Estado a favor de la expansión de la deman-

16 Este libro recoge las ponencias y debates de un seminario celebrado en 1994 con motivo del aniversario. Incluyo aquí las referencias de los participantes y sus ponencias como muestra del movimiento de temas e investigadores en torno al IEP de los años noventa. Cotler, Julio (editor): Perú 19641994. Economía, sociedad y política, Lima, 1995, 341 págs. [Cotler, Julio: "Introducción". Figueroa, Adolfo: "La cuestión distributiva en el Perú". Gonzales de Olarte, Efraín: "Transformación sin desarro1lo: Perú 1964-1994”. Álvarez Rodrich, Augusto: "Del estado empresario al estado regulador" (comentarios de Roberto Abusada y Javier Iguíñiz). Blondet, Cecilia: "El movimiento de mujeres en el Perú. 1960-1990". Golte, Jürgen: "Nuevos actores y culturas antiguas”. Tanaka, Martín: "Jóvenes: actores sociales y cambio generacional. De la acción colectiva al protagonismo individual" (comentarios de Luis Soberón y César Germaná). Grompone, Romeo: "El incierto futuro de los partidos políticos". Rubio, Marcial: "Los derechos humanos en la legislación y la práctica jurisdiccional del estado". Rospigliosi, Fernando: "Fuerzas Armadas, corporativismo y autoritarismo ¿qué ha cambiado en tres décadas?" (comentarios de Sinesio López, Francisco Eguiguren y Carlos Franco). Remy, María Isabel: "Historia y discurso social. El debate de la identidad nacional". Cornejo Polar, Antonio: "Literatura peruana e identidad nacional. Tres décadas confusas". Degregori, Carlos Iván: "El estudio del otro: cambios en los análisis sobre etnicidad en el Perú” (comentarios de José Luis Rénique y Alberto Escobar)].

17 Gonzales de Olarte, Efraín, y Samamé, Lilian: El péndulo peruano. Políticas económicas, gobernabilidad y subdesarrollo, 1963-1990, Lima, 1994, pág. 12. 
da interna y programas de contención de ésta, menor intervención estatal y liberalización del mercado exterior. Los bandazos políticos, mediante elecciones o golpes militares, debidos, en última instancia, a la gran fragmentación socioeconómica del país, habrían hecho ineficaces a las políticas económicas y, aún más, las habrían llevado a una espiral viciosa en que el péndulo se mueve cada vez más profundizando el subdesarrollo y haciendo más necesaria una nueva política de corrección. La salida de tal dinámica perversa estaría en detener el péndulo con algún acuerdo general sobre el tipo de estructura económica que se quiere y sacar buena parte de la dirección económica del país de la agenda política partidaria [Se me ocurre, aunque sin haberlo pensado mucho, que tal vez algo así se habría conseguido con el gobierno de notables de Valentín Paniagua en la transición que ahora vive el Perú. Sin duda, que este gobierno provisional se convertirá pronto en objeto de estudios que desde ya me parecerían importantes].

Lo interesante de la propuesta de Gonzales y Samamé en esta reseña está en la construcción de una matriz para el estudio conjunto de múltiples variables guardando la autonomía de éstas, pero también mostrando sus interdependencias, una matriz teórica ni teleológica ni monista. Otra cosa es, como ya vimos antes, si esta nueva metáfora también filtra y ordena los datos según la confirmación de su hipótesis y si podría cubrir el estudio de otros problemas más allá del asunto para el que fue diseñada.

\section{Interpretaciones recientes sobre la década de los noventa: entre el estupor y la esperanza}

Afortunadamente, el oprobio del gobierno de Alberto Fujimori no detuvo el trabajo en el Instituto de Estudios Peruanos pese a coyunturas difíciles, incluso se aumentó la actividad con más publicaciones, diversidad en los proyectos de investigación y actividades de formación externa. Esto se puede ver claramente en las memorias anuales del Instituto. Y por supuesto, la gestión del gobierno de Fujimori no podía dejar de llamar la atención, desde diversos trabajos tentativos a comienzos de la década hasta otros más ambiciosos de interpretación global. De estos últimos, voy a comentar cuatro libros, dos de ellos finalizados con anterioridad a la caída de Fujimori cuando aún no se lograba pronosticar su fin; y otros dos escritos durante los últimos meses de ese gobierno y los primeros tras la huida del dictador y su director de corrupciones. 
Una de las primeras interpretaciones globales de la década fujimorista proviene del área de economía. Efraín Gonzales de Olarte sólo tenía que alargar la perspectiva analítica que había montado, junto con Lilian Samamé, en El péndulo peruano para conseguir esa percepción sintética entre evolución económica, estructural social y cambios institucionales del Estado a través del estudio de las políticas económicas del gobierno fujimorista. Esta síntesis la logra en el libro El neoliberalismo a la peruana. Economía política del ajuste estructural, 1990-1997.

Para su diagnóstico, Gonzales de Olarte dedica un capítulo teórico al establecimiento de los modelos de ajuste estructural neoliberal que un gobierno tenía a su alcance como variantes del "consenso de Washington". En el correspondiente cuadro se indican las principales características de esos modelos..$^{18}$

MODELOS DE AJUSTE ESTRUCTURAL NEOLIBERAL POR COMBINACIÓN DE REFORMAS Y POLÍTICAS

\begin{tabular}{|l|c|c|c|c|c|c|c|}
\cline { 2 - 7 } \multicolumn{1}{c|}{} & \multicolumn{3}{c|}{ REFORMAS } & \multicolumn{2}{c|}{ POLÍTICAS } & Autonomía \\
\cline { 2 - 7 } \multicolumn{1}{l|}{} & Liberalización & Desregulación & Privatización & Macroeconómica & Sectorial & Social & NonELO \\
EXTREMO & Extrema & Total & General & $\begin{array}{c}\text { Restringida } \\
\text { Fiscal } \\
\text { Tipo de cambio } \\
\text { libre }\end{array}$ & No & No & Escasa \\
\hline $\begin{array}{l}\text { MODELO } \\
\text { INTERMEDIO }\end{array}$ & Alta & Mayoritaria & Mayoritaria & $\begin{array}{c}\text { Moderada } \\
\text { Fiscal y } \\
\text { monetaria } \\
\text { Tipo de cambio } \\
\text { supervisado }\end{array}$ & Parcial & Parcial & Moderada \\
\hline $\begin{array}{l}\text { MODELO } \\
\text { FLEXIBLE }\end{array}$ & Alta o media & Intermedia & Selectiva & $\begin{array}{c}\text { Activa } \\
\text { Manejo del tipo } \\
\text { de cambio }\end{array}$ & Avanzada & Avanzada & Alta \\
\hline
\end{tabular}

Tras identificar el ajuste estructural llevado acabo por el gobierno de Fujimori dentro del "modelo extremo", Gonzales de Olarte señalaba algunas de las causas del futuro desmoronamiento del régimen: la incapacidad del gobierno para pasar de las políticas de ajuste económico basadas en la destrucción de un Estado productor y regulador (privatizaciones, liberalización monetaria, laboral y comercial, eliminación de políticas sectoriales,

18 Gonzales de Olarte, Efraín: El neoliberalismo a la peruana. Economía política del ajuste estructural, 1990-1997, Lima, pág. 33. 
abstención en subsidiar a grupos productivos en crisis, reducción de la administración...) a políticas de estabilización y crecimiento basadas en programas económicos a largo plazo y fortalecimiento de instituciones autónomas. Esa incapacidad estaría más en el tipo de coalición que sustentaba la presidencia (militares, tecnócratas neoliberales y capital financiero internacional), viviendo de un Estado debilitado, una sociedad exhausta y una presidencia sin proyecto político propio, que en el plan mismo de ajuste estructural, por más ortodoxo que éste fuera. Al final se daría un divorcio entre economía y política que, si bien podría ya estar en los objetivos iniciales del ajuste, terminaría por bloquear las posibilidades de reconducción de las reformas hacia una fase de expansión productiva.

La propuesta de Gonzales de Olarte tiene las virtudes de un modelo casi weberiano que, con el diseño de situaciones teóricas, consigue un sistema de comparaciones con gran valor interpretativo. Pero en el esquema que nos presenta hay un factor decisivo cuya caracterización es algo ambigua: el papel del Estado. Grosso modo, señala que el Estado ha sido, a lo largo del siglo XX, el principal, casi único, agente articulador de una sociedad nacional de por sí fragmentada e incapaz de definir un proyecto nacional a largo plazo. Cualquier proyecto de este tipo tendría ganadores y perdedores, aunque fuera en términos relativos, pues se basaría en la hegemonía de algún conjunto de intereses particulares. Sin embargo, la fragmentación y aislamiento de estos intereses particulares hacía también que cualquier proyecto fuera insostenible justamente por no incorporar a los intereses opuestos: una solución nítidamente exportadora iría en detrimento de la demanda interna, la industrial nacional, la salud fiscal del Estado y la autonomía externa de éste, lo que tendería a producir un reflujo en sentido contrario sin incorporar a los intereses exportadores. Éste sería el juego pendular de suma cero que ya vimos en el libro de Gonzales y Samamé. Ahora bien, si esta dinámica ha sido endógena a largo plazo y la intervención extranjera no ha marcado la oscilación entre un extremo y otro del péndulo, entonces el Estado nunca habría ganado un mínimo de autonomía ni resuelto la fragmentación de intereses en su propio seno, y su capacidad de articulación de la nación peruana no habría pasado de lo geográfico e ideológico, por tanto el extremismo del ajuste estructural fujimorista no podría ser interpretado como un desplazamiento de la capacidad articuladora del Estado hacia la preeminencia del mercado en tal labor, ni siquiera como un "desborde" del Estado por parte del mercado — que seguiría tan desintegrado como "siempre"-, pues los diques de aquel siempre habrían sido débiles contra el oleaje de los inte- 
reses particulares. Por otra parte, si las políticas económicas no son tan endógenas y la intervención extranjera es más importante, entonces el esquema del péndulo pierde capacidad heurística. Y si la mayor o menor capacidad de sujeción (más que articulación) del Estado sobre la sociedad respondiera a otro tipo de intereses menos económicos, como los burocráticos, militares, geoestratégicos, o la simple inercia ante la falta de alternativas en un escenario regional ya nacionalizado, entonces la adopción de una u otra política económica perdería centralidad en la vida del Estado.

Entiendo que bajo la tesis de que el Estado peruano ha sido el principal cemento de una sociedad fragmentada pero que a su vez, por esa característica transversal de la sociedad, ese mismo Estado no habría alcanzado ni la autonomía ni los recursos suficientes para consolidar la unidad nacional, hay una hipótesis de muy improbable verificación: el que una sociedad más homogénea y articulada implique un Estado más autónomo y coherente en sus políticas a largo plazo. Esta hipótesis parece funcionar como marco normativo no explicitado ${ }^{19}$ en contraste con una realidad cargada de correlaciones estadísticas adversas. El caso es que esta hipótesis alternativa sólo se podría verificar en un Perú desarrollado e integrado, pero poco nos dice de cómo se llega a tal situación. Y aún más, si durante todo el siglo XX el Estado peruano hubiera sido capaz, pese a la fragmentación social, de mantener una misma política económica, ¿se habría alcanzado esa relación virtuosa entre gobierno y sociedad articulada en pos del desarrollo estable?

El segundo libro que quiero reseñar aquí es de Fernando Rospigliosi: Montesinos y las fuerzas armadas. Cómo controló durante una década las instituciones militares, de diciembre de 2000. Es menos ambicioso en cuanto a planteamientos teóricos que los ya revisados, aunque tiene sus propuestas parciales, y consiste en un compendio de textos publicados por el autor en la segunda mitad de los años noventa (los más recientes, aparecieron en la revista Caretas en los meses de mayo y julio de 2000). Tiene un estilo más cercano al periodismo de investigación (Rospigliosi es columnista semanal en la revista Caretas y habitual colaborador del diario peruano La República) que a textos sociológicos. Con este libro defiende la tesis de que la clave del poder político en el Perú de los noventa ha sido Vladimiro Montesinos Torres, ex capitán del ejército, del que fue expulsado por traición a la patria en 1976, abogado de narcotraficantes en los años ochenta y asesor del presidente Fujimori desde poco antes de su investidu-

19 Algo sí se expone en el capítulo segundo de Gonzales de Olarte, Efraín, y Samamé, Lilian: El péndulo peruano. 
ra como Jefe del Estado y personificación de la nación (según rezaba en la Constitución de 1979 y continua rezando en la de 1993). La proposición más acabada de esta tesis — cuya detallada demostración con un amplio glosario de pesquisas, documentos, confidencias, noticias, etc., hilvana todo el libro- podría ser la siguiente:

En Latinoamérica ha habido muchísimas dictaduras en los últimos dos siglos. Pero nunca ha existido una en la que el jefe de los servicios de inteligencia controle el poder, y que esos servicios dominen a las fuerzas armadas. Rafael Leonidas Trujillo tuvo a su Johnny Abbes, Manuel Odría a su Esparza Zañartu, Augusto Pinochet a su Manuel Contreras, Juan Domingo Perón a su José López Rega. Pero jamás ha habido un caso en el que un Vladimiro Montesinos tenga su Alberto Fujimori, como sucedió en el Perú entre 1990 y el 2000.

En el Perú, con una historia republicana jalonada de dictaduras, en ningún momento los espías mandaron a las fuerzas armadas. Eso ocurrió por primera vez con Montesinos.

Alberto Fujimori no fue un simple títere de Montesinos, si bien éste lo manipuló sistemáticamente. Fujimori fue un cómplice y un socio. Él supo perfectamente quién era Montesinos desde el primer momento. ${ }^{20}$

Con estos párrafos, Rospigliosi distingue el factor fundamental en la definición del régimen político peruano de los años 90 , una dictadura personal mafiosa, en que las instituciones en que basa su poder, fuerzas armadas y presidencia de la República, son corrompidas por un personaje siniestro. Esto sería posible por la necesidad que ambas instituciones se tenía entre sí, o mejor, por la necesidad que ambas tenían de que la otra la apoyase y le diese todo el poder discrecional sin fiscalizar en que lo empleaba. Y la conexión entre esas fuerzas armadas empeñadas en una guerra sucia contra el terrorismo y un presidente sin partido, ni programa o grupo económico que lo apoyara, fue la basa a jugar por Vladimiro Montesinos. El golpe de estado del 5 de abril de 1992 sellaría esta relación cada vez más perversa y su poder se basaría crecientemente en la corrupción y el chantaje, dejando de lado los objetivos "pacificadores" de los militares, la legitimación plebiscitaria de Fujimori y la "estabilización" macroeconómica neoliberal. Este proceso afectaría, incluso, a las fuerzas armadas y sus relaciones con la sociedad civil. El manejo arbitrario y corrupto que Montesinos habría hecho de los ascensos y los destinos dentro de las armas militares habría roto con toda racionalidad reglamentaria o tradicional del

20 Rospigliosi, Fernando: Montesinos y las fuerzas armadas. Cómo controló durante una década las instituciones militares, Lima, 2000, pág. 43. 
funcionamiento de las instituciones armadas, entrampándolas en la ineficiencia y la mediocridad hasta el punto de poner en riesgo la integridad territorial del país. Además, las relaciones institucionales entre fuerzas armadas y sociedad civil habrían quedado seriamente comprometidos en situaciones de sospecha y desconocimiento difíciles de superar.

El principal mérito del trabajo de Rospigliosi es haber descrito con detalle una trama de poder siniestra y anti-institucional, sin caer en la necesidad histórica o en la explicación según algún rasgo cultural o social más allá de las actuaciones concretas de los protagonistas. Pero este iluminar unas zonas oscuras del poder deja en penumbra un conjunto de relaciones sociopolíticas en que actuaba la coalición gobernante. Me refiero al manejo de la legitimidad del gobierno incluso cuando golpeó de muerte la Constitución por la que había sido elegido y, sobre todo, a la incapacidad de que se articulara una oposición creíble. El caso es que, en 1990, Fujimori significó un conjunto de rechazos más que una posición propia definida y que durante su mandato jugó con éstos evitando su cristalización en un programa político concreto, más bien, haciendo de esos rechazos a los partidos políticos y la intervención del Estado en la vida popular un discurso de legitimación de lo no-político, del no-debate, de lo no-formalizado: el gobierno recaudaba o repartía, pero no formalizaba. Todo este campo de acciones es el que no trata Rospigliosi en su análisis y que, al quedar en la penumbra, hace relucir a Montesinos y su trama. Por supuesto que Montesinos y el Servicio de Inteligencia Nacional tuvo mucho que ver en la gestión mafiosa de ese conjunto de rechazos e informalidades sociales, pero no logra explicar del todo la falta de alternativa política o por qué sí la habría en las elecciones del 2000.

Más atento a estos últimos problemas se muestra el libro de Carlos Iván Degregori La década de la antipolítica. Auge y huida de Alberto Fujimori y Vladimiro Montesinos. Este libro ya tiene en cuenta las tortuosas elecciones de 2000, los acontecimientos en torno al 28 de julio de ese año, con la Marcha de los Cuatro Suyos, el descubrimiento de la videoteca de Montesinos, la huida y persecución de éste, la renuncia desde el Japón de Fujimori y la posterior instalación de un gobierno provisional de "notables". Estos últimos acontecimientos están muy presentes y casi fuerzan a la relectura de buena parte del texto que fue escrito con anterioridad a los mismos. La tesis central con que Degregori quiere que se lea su trabajo, con la que él mismo también quiere leerlos, es la de que los noventa han sido "la década de la antipolítica. Y la antipolítica es efímera como la antimate- 
ria, volátil como el alcohol y potencialmente explosiva como la nitroglicerina. Sólo puede subsistir con el balón de oxígeno que le proporcionan los «poderes fácticos», externos al sistema político que la antipolítica aborrece y busca demoler". ${ }^{21}$

El principal problema es, por tanto, la demolición del orden político como "régimen" de lo público, de la búsqueda de la vida nacional, de la lucha entre proyectos alternativos, con vehemencia, pero con el respeto y la extensión de la publicidad, de la argumentación, de las reglas compartidas..., una vida con todos los problemas que se quiera, pero sin paranoia, sin el uso del secreto y el miedo. Degregori nos ofrece un amplio registro de esa demolición en sus principales momentos. Al comienzo, casi sin protagonista o con muchos, como el efecto dominó de la crisis de régimen entre la guerra, la bancarrota económica y el colapso de los partidos políticos en torno a las elecciones de 1990. Pronto iniciaron las operaciones de acoso y derribo con las declaraciones en la televisión y los tanques en las calles, como en abril de 1992. Luego, cuidaron el amarre del poder encubierto, con la ley de "amnistía" de 1995 a favor de los violadores de derechos humanos, y la consolidación del poder "escénico" (más que público en sentido político, pues el acceso al mismo era restringido y distorsionado con manipulaciones secretas) con la reelección de 1995. A partir de ahí, todo serían movimientos miasmáticos de un cuerpo sin esqueleto, siempre en la incertidumbre y la crisis, creciendo como abismo:

La situación de emergencia política, supuestamente temporal, se volvió permanente. Por eso las huellas de ese nacimiento violento se exhiben hasta hoy y el gobierno se vuelve cada vez más autoritario, desligándose de cualquier representación hasta convertirse en un régimen de camarilla, mafioso y autista, que a estas alturas representa fundamentalmente un pasado que se resiste a serlo. ${ }^{22}$

Degregori logra un magnífico "cuaderno de campo" provisto de observaciones documentadas y preguntas contundentes. En aquel tono de los fundadores del IEP, parece que se pregunta constantemente: ¿qué ha pasado y, probablemente, sigue pasando en el Perú para que la vida colectiva nacional sea tan vulnerable? Y por razones de oficio, casi toda su indagación se dirige a entender el manejo de la comunicación social y la construcción (destrucción) del mundo simbólico — discursos, imágenes, códigos, dispositi-

21 Degregori, Carlos Iván: La década de la antipolítica. Auge y huida de Alberto Fujimori y Vladimiro Montesinos, Lima, 2000, pág. 19.

22 Ibídem, pág. 14. 
vos, medios, etc.- de esa vida colectiva. En este contexto más ambicioso, una pregunta explícita de Degregori alcanza toda la fuerza de su vehemente esfuerzo y protesta: “¿qué pasó en el espacio público para que la palabra se desgastara hasta desaparecer?" ${ }^{23}$ La palabra desaparece no sólo metafóricamente, sino también físicamente con el secuestro de los medios de comunicación mediante corruptelas y el hartazgo de los sentidos con las mentiras, el insulto, la persecución, o la amenaza y la muerte. La mayor parte del libro está dedicada al estudio de este desgaste metonímico de la sociedad, al análisis de la prensa amarilla (chicha, popular) y de los operativos de manipulación (implantes) de la memoria y el olvido. Pero en la lucha contra el gobierno fujimorista, Degregori atisba el resurgir de esa palabra pública, de la promesa peruana, en la forma del río humano que conformó las jornadas nacionales de protesta contra la investidura inconstitucional de Fujimori como presidente de la República el 28 de julio de 2000:

Al mismo tiempo, se actualizó la vigencia de una comunidad nacional que se anclaba difusamente en la historia a través del calificativo «de los cuatro suyos» y que dejaba de ser sólo imaginada para corporizarse durante el paso de las delegaciones provinciales, unánimemente ovacionadas [...] Conforme el espacio público volvía a ser civil, las celebraciones oficiales se replegaban hacia las instalaciones militares. La otra marcha, el desfile militar [que se realiza cada 29 de julio con motivo de las fiestas patrias], se realizó por primera vez en el Pentagonito. ${ }^{24}$

En estas consideraciones, como en cierto tono que recorre el libro, aparece un aspecto del análisis que, estimo, distorsiona la claridad del problema de la antipolítica como Degregori lo había presentado al comienzo del volumen. No sé si en los primeros ensayos de éste todavía la oposición a Fujimori no había ganado la importancia posterior y la demolición de la política seguía siendo irresistible (o si acaso sólo tenía fondo en la disolución de la sociedad y el Estado). El caso es que estas consideraciones hacen pensar en que algo fundamental del Perú, de su pueblo, había sabido resistir a la penetración indecente del poder fujimorista. Ese algo no sólo es el pueblo que reaparece para retomar el protagonismo, sino la "bondad" genérica de éste, de la ciudadanía como resistencia, contra la que el poder privado (secuestrado) despliega una amplia e intensa gama de manipulaciones, chantajes, corrupciones, muertes, etc., para así desarticular esa bondad y someterlo. Exagero el tono que esto tiene en el trabajo de Degregori, pero es

23 Ibídem, pág. 106.

24 Ibídem, pág. 267 
algo presente que dificulta el pensar la antipolítica como una amenaza, un ataque contra la política y no contra la justicia de un pueblo, de una comunidad victimada. También esto, pero justamente entre el gobierno y el ciudadano que demanda justicia "debería" estar la política como formas (instituciones y prácticas) que impidan la exclusión, que abran el espacio público, que verifique que en toda polémica siempre hay más de dos, siempre otro al que los oponentes pueden recurrir para no caer en la falacia de la guerra como metáfora de la política "real" en la que el primero en morir es ese otro: el juez imparcial, el sistema de partidos, la prensa libre, el ciudadano de a pie, la manifestación, el colectivo de afectados, la policía profesional, el acalde fiscalizado y reivindicativo, la vida privada, el Estado de derecho, las personas físicas y morales..., el pueblo incorpóreo de las votaciones..$^{25}$

El ultimo libro que quiero traer aquí, El fujimorismo: ascenso y caída de un régimen autoritario, está firmado conjuntamente por Julio Cotler y Romeo Grompone, aunque cada uno presenta por separado su propio ensayo. Ambos textos fueron preparados con anterioridad a la huída de Fujimori y tratan de incorporar, posteriormente, el nuevo escenario de transición que ésta abre en el Perú.

El ensayo de Julio Cotler, "La gobernabilidad en el Perú: entre el autoritarismo y la democracia", tiene dos asuntos principales de reflexión: el primero en importancia y eficacia sería "la participación de diferentes actores internacionales en la escena nacional", esto es, que la intervención de gobiernos extranjeros (Estados Unidos), organismos internacionales (FMI, OEA, BM) y grupos privados (capital extranjero y grupos internacionales de presión) ha sido clave en la evolución que la vida interna del Perú ha seguido en los años noventa debido a la debilidad institucional del Estado peruano y a la situación de crisis extrema del país que ponía en peligro la estabilidad regional; el segundo asunto es la tensión entre gobernabilidad y democracia como razón a favor de soluciones autoritarias cuando se las confronta (lo hizo el gobierno de Fujimori, pero también algunos operadores internacionales) o a favor del régimen democrático cuando se muestra su mutua dependencia (discurso de la OEA y de la oposición interna a Fujimori).

25 Desde mi punto de vista, corporizar al pueblo es el mayor riesgo para cualquier vida democrática. Por ejemplo, la fragmentación social o étnica, sólo sería un problema para la democracia si se pretende un pueblo corporal preeminente, sea éste mayoritario o minoritario, pues esa corporeidad no es procesada en el régimen político de las reglas y las convenciones manejables en el tiempo mediano de una vida humana, sino en la arbitrariedad y las necesidades de la larga historia. 
En un estilo rápido y desenvuelto - sin uso de citas, estadísticas o marcos teóricos duros-, Cotler recupera la tesis de una sociedad fragmentada siempre al borde de la disolución, con instituciones estatales débiles y un crecimiento exponencial de expectativas sociales que favorecen a los programas populistas económicamente irresponsables. Con este cuadro básico, la sociedad peruana habría entrado en barrena a finales de los ochenta y, a partir de las elecciones de 1990, dos únicas instituciones parecen dispuestas a detener la caída: las fuerzas armadas y la presidencia de la República. ${ }^{26}$ Con Vladimiro Montesinos como orquestador, estas dos instituciones entran en coalición con empresarios y tecnócratas nacionales, capital extranjero y el apoyo de la CIA estadounidense, para ejecutar un plan de restauración del orden (económico y militar) y de deflación de las expectativas sociales. La solución es claramente autoritaria y, por estar en contra del nuevo orden internacional liderado por Estados Unidos, descalificada internacionalmente. Sin embargo, la coalición autoritaria logra un amplio respaldo popular y se hace fuerte asumiendo un programa ajeno de reconstrucción de la democracia en una forma más gobernable, aunque también más autoritaria. Todo parece marchar más o menos bien, hasta que crece el aislamiento de la coalición gobernante drenada por la corrupción y los personalismos. También surgen problemas con la estabilización económica, con el respeto al Estado de derecho y con el reflote de medidas populistas para salvar al gobierno de Fujimori de su creciente impopularidad. Ninguna de estas cosas gustaría a los apoyos internacionales del régimen que comienzan a jugar en su contra, con lo que su caída estaría casi prediseñada. De nuevo la intervención internacional estaría en la hora final del fujimorismo.

Por supuesto, la argumentación de Cotler es mucho más detallada y cuenta con numerosos textos ya publicados por el autor con anterioridad. ${ }^{27}$ Ahora bien, esa misma argumentación sobre la importancia de la intervención internacional en la vida interna del Perú, también nos podría llevar a una lectura dependentista en que la debilidad del Estado peruano no fuera tanto hacia su sociedad como hacia las presiones externas y, a la inversa, no sólo se debiera a una insoluble fragmentación nación sino también a la

26 También se podría interpretar, sin forzar los hechos, que estas dos instituciones habrían tenido una importante responsabilidad en la crisis del Perú.

27 Uno de los más recientes trata el proceloso mundo del narcotráfico, que sería otro de los asuntos transversales del Perú contemporáneo, fundamental para entender la década del oprobio fujimorista. Cotler, Julio: Drogas y política en el Perú, la conexión norteamericana, Lima, 1999. 
fragmentada e interesada participación internacional. Por ejemplo, la OEA condenaba el golpe de 1992, pero poco después la Telefónica Española (entonces una empresa mayoritariamente estatal) avalaba el programa fujimorista con 2.200 millones de dólares sin ninguna fiscalización (ni sobre el gobierno peruano ni sobre la multinacional española). ${ }^{28} \mathrm{O}$ mientras la Unión Europea y el Departamento de Estado de Washington abogaban por la transparencia democrática y el respeto de las leyes, el FMI avalaba la renegociación de la deuda externa peruana en el más sospechoso secretismo y con los resultados menos favorables para la hacienda del país andino. En fin, también hay la más cínica fragmentación en la escena global.

Para terminar, trataré de reseñar el proteico ensayo de Romero Grompone "Al día siguiente: el fujimorismo como proyecto inconcluso de transformación política y social". Pese a este impreciso título, el ensayo de Grompone es la más ambiciosa y académica interpretación sobre el gobierno de Fujimori y el Perú actual de las revisadas aquí. Opino así no porque su análisis sea el más profundo, algo en que no supera al de los otros autores, ni porque sus hipótesis estén desarrolladas con más detalle y abarque más variables (en parte, esto último sí), sino porque sus reflexiones giran constantemente en torno a un problema "normativo" fundamental para la democracia: que hay que defender a ésta "como un régimen político y no sólo como apelación vaga a una forma de convivencia social". ${ }^{29}$ Quiero entender que aquí se va más allá de la idea de régimen como juego reglado convencionalmente, alcanzando a proponerlo como propiciador del juego hasta el punto de asumir que la definición de éste, de la democracia, es meta y regla para cada participante. Para precisar más la lectura del "días después" que hace Grompone (y aclarar, en lo posible, mi previa opinión), es oportuno traer aquí parte de las exhortaciones con que termina su texto:

28 A partir de ahí, España se convirtió en el principal inversor extranjero en el Perú, normalmente utilizando como lanzaderas algunas empresas estatales en proceso de privatización en España, tras la que irían los bancos, también beneficiarios de las privatizaciones españolas. El 28 de julio de 2000, el único representante de alto nivel enviado por un gobierno de la Unión Europea fue el vicepresidente español Mariano Rajoy. Claro, también los empresarios peruanos han pasado por Madrid para defender el mercado y la estabilidad de las inversiones, como ya pasó varias veces el candidato Alejandro Toledo con un discurso más social pero igualmente tranquilizador para las inversiones españolas.

29 Esta frase la usa Grompone para comentar las posiciones de la izquierda ante la caída del fujimorismo, pero es una proposición que atraviesa su propia interpretación. Grompone, Romeo: "Al día siguiente: el fujimorismo como proyecto inconcluso de transformación política y social", en Cotler, Julio, y Grompone, Romeo: El fujimorismo: ascenso y caída de un régimen autoritario, Lima, 2000, pág. 166. 


\begin{abstract}
El clima intolerable del autoritarismo, hasta el mismo desconcierto en que hoy viven muchos de los que lo apoyaron enfrentados a los patéticos acontecimientos recientes, exige reconocer que aun cuando haya dificultades históricas para instaurar el Estado de Derecho - que no es el caso detallar aquí-, ello es una tarea impostergable si no queremos caer en este envilecimiento de las relaciones personales que promovió el fujimorismo con su intolerancia y su desprecio a los ciudadanos y su empecinado propósito de enfrentar a unos con otros. Esta corrosión de los vínculos sociales traslada a las relaciones con los otros lo que en el plano político se vive como falta de derechos y garantías [...] En un plano más profundo se trata de luchar contra esta devaluación de palabras y argumentos que el fujimorismo impuso y que va a ser un lastre difícil de arrojar [...] Y para ello tiene que estar claro para las grandes mayorías que se abre una perspectiva de cambio que va desde la vigencia de comportamientos éticos, a una inevitable transformación social, llevada con realismo pero con una decisión firme de llegar tan lejos como se pueda. ${ }^{30}$
\end{abstract}

Por demás, el trabajo de Grompone revisa las condiciones políticas y sociales en que tuvo lugar la práctica antipolítica del gobierno de Fujimori. Y la tesis transversal a su lectura es que una reducida camarilla de personajes (en extremo, Fujimori y Montesinos, los únicos sin instituciones a que responder, Hermoza Ríos, mal que bien, era responsable ante sus compañeros de armas) ocupó la crisis del régimen político peruano para vivir en y de ella. Los ajustes económicos, el regreso a la escena internacional, los planes de pacificación ejecutados por los militares, la derogación de la Constitución de 1979 y la promulgación de la de 1993, la instalación de "los islotes de eficacia" en la administración, la concentración de las políticas de asistencia social en el macro Ministerio de la Presidencia, la permanente presencia en los medios de comunicación..., resultan actuaciones parciales que la camarilla gestiona en un amplio campo de fuerzas (de batalla) sin institucionalizar. Al comienzo, muchos de esos planes que respondían a grupos que querían utilizar el inesperado poder de la camarilla - capital financiero, militares, tecnócratas - cubren la escena estabilizando algunos "índices" (inflación, violencia, relaciones exteriores) macropolíticos. Pero, tras los éxitos provisionales, la camarilla comenzará a alimentarse de esos mismos planes de estabilización, drenará sus programas y los irá sustituyendo con su propia lógica miasmática de corrupciones y chantajes. En los estertores del proceso, la propia camarilla se auto consumirá como combustible para su huida, apareciendo como perseguidora de sus fechorías (se auto-denuncia en el tráfico de armas, se auto-filma en las corrupciones).

30 Ibídem, págs. 172-174. 
Con todo esto es difícil entender por qué Grompone sugiere en el título de su ensayo que el fujimorismo fuera un "proyecto inconcluso de transformación política y social", pues no hay manera de identificar ese proyecto y esa transformación. ¿No se trataría más de un parásito, de una tenia política, de un virus oportunista que aprovechando la debilidad del país infecta sus partes más delicadas y se enquista en ellas? Pero también puede ser que sólo se tratase de un grupo de "ciudadanos" ambiciosos que aprovechó unas oportunidades inusitadas en propio beneficio mientras dejaba hacer y deshacer a cuantos tenían poder a cambio de sus apoyos. Seguramente eran eso, personas como cualquier otra del Perú u otro país, que sin reparos morales (algo que no está inscrito en los genes) dispusieron de sus puestos políticos de manera privada y no hubo manera de detenerlos (aún siguen huidos).

\section{Algunas consideraciones finales}

Tras 37 años, el Instituto de Estudios Peruanos sigue produciendo interpretaciones del país al que dedica sus esfuerzos, aunque en los años noventa se haya perdido cierta capacidad para crear imágenes integradoras y el desaliento haya impregnado el trabajo de sus investigadores. La idea más común en los textos sobre el fujimorismo es la de la antipolítica, un proceso que parece afectar incluso a la propia teoría política desmontando los parámetros para la investigación social. Carlos Iván Degregori plantea el problema mostrando parte de su desconcierto:

Cómo la mayoría no advertimos en su real dimensión hasta bastante después la cobardía presidencial y, más importante, el poder de Montesinos que posiblemente era ya entonces el más poderosos de los siameses. Fueron algunos periodistas de investigación quienes primero advirtieron la magnitud del peligro que significaba Montesinos y su enorme poder: Gustavo Gorriti, Fernando Rospigliosi, Edmundo Cruz, Ricardo Uceda fueron, entre otros, precursores desde las revistas Sí y Caretas, y desde el diario La República. En la reacción tardía de la mayoría de analistas políticos pesó posiblemente la cercanía de los acontecimientos, pero también la influencia de los debates académicos, que a veces se convierten en anteojeras que recortan nuestro campo de visión en vez de profundizarlo. ${ }^{31}$

Efectivamente, la academia, más que la teoría, puede convertirse en un límite, en unas anteojeras que nos mantienen en el surco sin atender a

31 Degregori, Carlos Iván: La década de la antipolítica, pág. 352. 
otros aspectos de la sociedad. Pero también es posible que eso pasara más en el Perú previo al oprobio fujimorista que a consecuencias de éste. Una investigación más detallada del propio trabajo del IEP (más si la ampliamos a los corpus de otros centros de investigación) nos podría dar luz sobre esta hipótesis. De momento deberíamos ser escépticos con los propios planteamientos de Carlos Iván Degregori; tal vez el trabajo de investigación no sólo sea el dar una buena y real descripción de la sociedad, tal vez también sea proporcionar el cuerpo normativo sobre la vida colectiva que se quiere desde donde criticar esa sociedad o apostar por su defensa, y someter a la crítica de los demás nuestra propia propuesta de sociedad. Incluso, ¿cómo se podrían comparar periodos históricos distintos, sociedades distintas, proyectos distintos, sin el "amparo" de un esquema normativo sobre la vida buena? Y sin embargo, es un grave peligro confundir la descripción de la sociedad con nuestra propuesta de vida colectiva.

La mayor parte de la producción investigadora del IEP ha tenido un sesgo social, dando prioridad a las estructuras e identidades sociales en sus argumentaciones. Sin duda era un trabajo que había que hacer y que debe mantenerse, pero también parece claro ahora que es muy importante investigar los requerimientos institucionales del país, desde los estatales hasta los económicos y los de representación política en sus diversos niveles. Entre estos requerimientos también están los de la propia investigación de los asuntos sociopolíticos: el cuidado de los métodos, de la argumentación, de los fines internos y externos al estudio, de la ubicación social del trabajo intelectual, etc. Tal vez, más que visiones hegemónicas del Perú, en los años noventa lo que se haya echado de menos haya sido la capacidad de una crítica que convenciera de lo funesto de lo que ocurría; también indicar por dónde podrían estar las alternativas, pero sobre todo haber desmontado el discurso de la antipolítica que se alimentaba del raquitismo discursivo en que vivía la democracia. 